\title{
Posterior interosseous nerve palsy in a child associated with recurrent dislocation of the head of the radius
}

\author{
Case report
}

\author{
R. Shane Tubbs, Ph.D., P.A.-C., ${ }^{1}$ Christoph Griessenauer, M.D., ${ }^{1}$ Elias Rizk, M.D., ${ }^{1}$ \\ Mohammadali M. Shoja, M.D., ${ }^{1}$ Stephen F. Pehler, M.D., ${ }^{2}$ \\ John C. Wellons III, M.D., M.S.P.H., ${ }^{1}$ and Michael J. Conklin, M.D. ${ }^{2}$ \\ ${ }^{1}$ Pediatric Neurosurgery and ${ }^{2}$ Pediatric Orthopedics, Children's of Alabama, Birmingham, Alabama
}

\begin{abstract}
Injuries to the posterior interosseous nerve (PIN) appear to be very uncommon in children. In this paper, the authors describe a 9-year-old boy with a radial malunion and radial head instability that resulted in PIN compression. Surgical decompression via transection of the overlying supinator muscle with correction of the radial deformity and instability resulted in complete return of PIN function. The clinician should be aware of anterior dislocation of the radial head as a cause of PIN injury. Based on the authors' experience, nerve decompression and correction of the bone deformity result in return of normal PIN function. (http://thejns.org/doi/abs/10.3171/2013.1.PEDS12411)
\end{abstract}

KEY WORDS - $\begin{gathered}\text { peripheral nerve } \\ \text { anatomy } \\ \text { decompression }\end{gathered}$

$\mathrm{I}$ $\mathrm{N}$ the cubital fossa, near the radiohumeral joint, in close proximity to the lateral epicondyle, the main radial nerve trunk branches into 2 terminal branches: a superficial branch, which supplies the skin of the radial dorsal aspect of the hand and distal forearm; and a deep, primarily motor branch that travels down the posterolateral forearm through the supinator muscle to become the PIN (Fig. 1). ${ }^{13,19}$ On average, the proximal PIN can be identified $5 \mathrm{~cm}$ inferior to the lateral epicondyle. ${ }^{18}$ The PIN is crossed by lateral branches of the recurrent radial artery and vein, the so-called leash of Henry., 9,10,20 The PIN descends, passing over the anterior aspect of the radiohumeral joint, and travels deep to the superficial lamina of the supinator muscle. ${ }^{16}$ The PIN then travels to the posterior aspect of the forearm, around the lateral side of the radius, and exiting between the fibers of the supinator muscle, and is prolonged distally to the middle of the forearm..$^{3,6,16,17}$

The proximity of the PIN to the radial head makes the nerve susceptible to injury. The injury may be from an acute traumatic event or a delayed manifestation secondary to radial head dislocation. In this paper we report

Abbreviation used in this paper: $\mathrm{PIN}=$ posterior interosseous nerve. a relatively uncommon case of radial head dislocation in a child with delayed PIN syndrome. Surgical intervention resulted in PIN recovery.

\section{Case Report}

History and Examination. This 9-year-old boy presented with weakness during right wrist extension after he had suffered multiple right forearm fractures over the course of a 1-year period prior to his evaluation. The fractures were treated at an outside facility using long-arm cast application. The family presented to the orthopedic clinic, noting decreased use of the boy's right hand and deformity of the forearm. His medical history was significant for mental retardation and legal blindness from congenital glaucoma. On physical examination with the forearm in a neutral and pronated position, the radial head was dislocated anteriorly but was reducible in supination. An apex anterior angulation of the proximal radius was palpable. Motor examination was notable for absent metacarpophalangeal joint extension and thumb extension. Triceps brachii, brachioradialis, and extensor carpi radialis longus functions were normal. Radiographs of the right forearm disclosed a malunion of a proximalthird radius fracture and anterior dislocation of the radial 


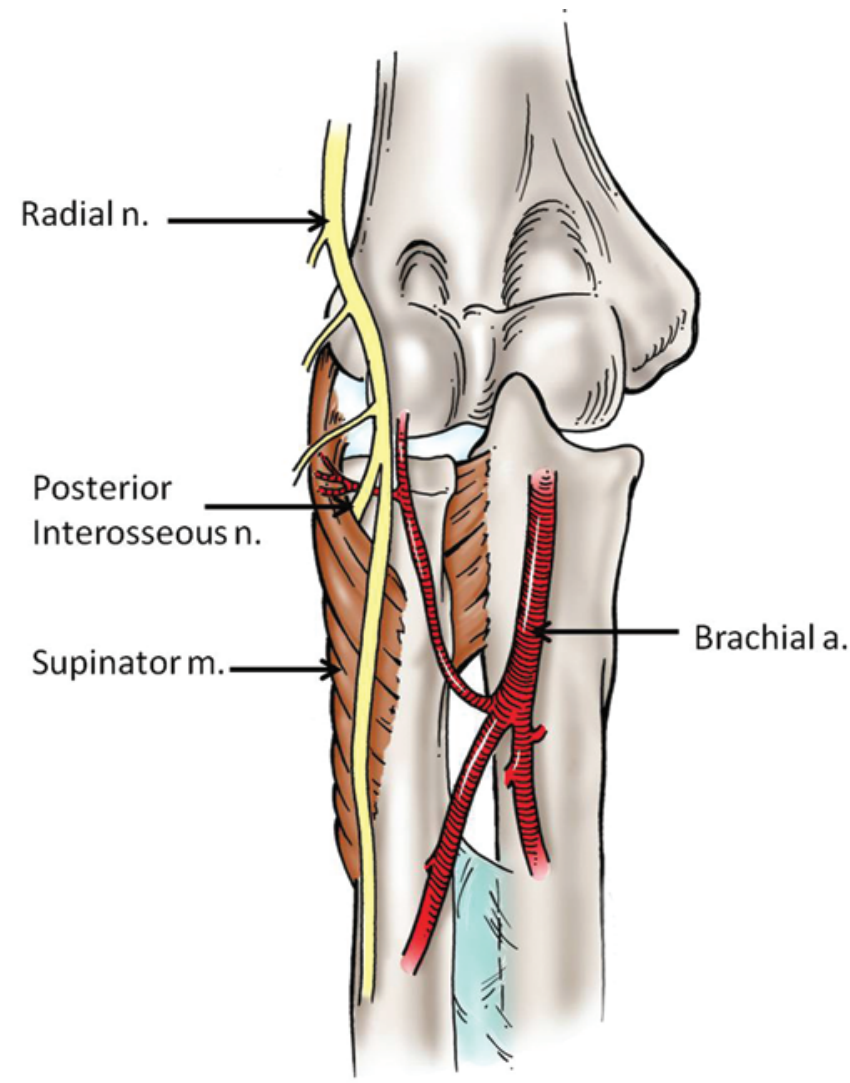

FIG. 1. Schematic drawing of the proximal forearm noting the radial nerve (Radial $n$.) crossing anterior to the lateral epicondyle and near the radial head, branching into superficial (cutaneous) and deep (PIN) branches. Note the course of the PIN through the supinator muscle (Supinator $\mathrm{m}$.). Brachial $\mathrm{a} .=$ brachial artery. Modified from Tubbs et al.: $\mathrm{J}$ Neurosurg 104:796-799, 2006. head (Fig. 2A). The PIN palsy was believed to be secondary to recurrent radial head dislocation and neurosurgery was consulted for peripheral nerve repair and/or decompression to be performed in conjunction with bone corrective procedures.

Operation and Postoperative Course. Intraoperatively, pronation of the forearm resulted in radial head dislocation, and stretch of the PIN at the arcade of Frohse was visualized (Video 1).

VIDEo 1. Clip showing the PIN exposed between the 2 handheld retractors. With pronation, the radial deformity is shown displacing the nerve laterally, and with supination, the nerve is less compressed. Click here to view with Media Player. Click here to view with Quicktime.

The PIN was decompressed through the supinator muscle (Fig. 2B). No obvious neuroma was identified and the nerve had a good vascular appearance. After correction, maximal pronation and supination revealed stability of the radial head. Five months postoperatively the patient has experienced a complete return of PIN function and healing of the radius without deformity or subluxation (Fig. 2C). Elbow range of motion is $0^{\circ}-150^{\circ}$ and supination and pronation are $70^{\circ}$ and $80^{\circ}$, respectively.

\section{Discussion}

In this paper, we present a case of an angulated radius fracture and recurrent radial head dislocation resulting in PIN palsy. Posterior interosseous nerve palsies have been previously associated with unreduced radial head dislocation, proximal ulnar fractures with dislocation of the radial head, and anterolateral dislocation of the radial head. ${ }^{8}$ Other reported causes of PIN palsy include neuromas, ${ }^{12}$ schwannomas, ${ }^{3}$ traumatic aneurysms of the posterior interosseous artery, ${ }^{4}$ neurofibromas, ${ }^{11}$ ganglion
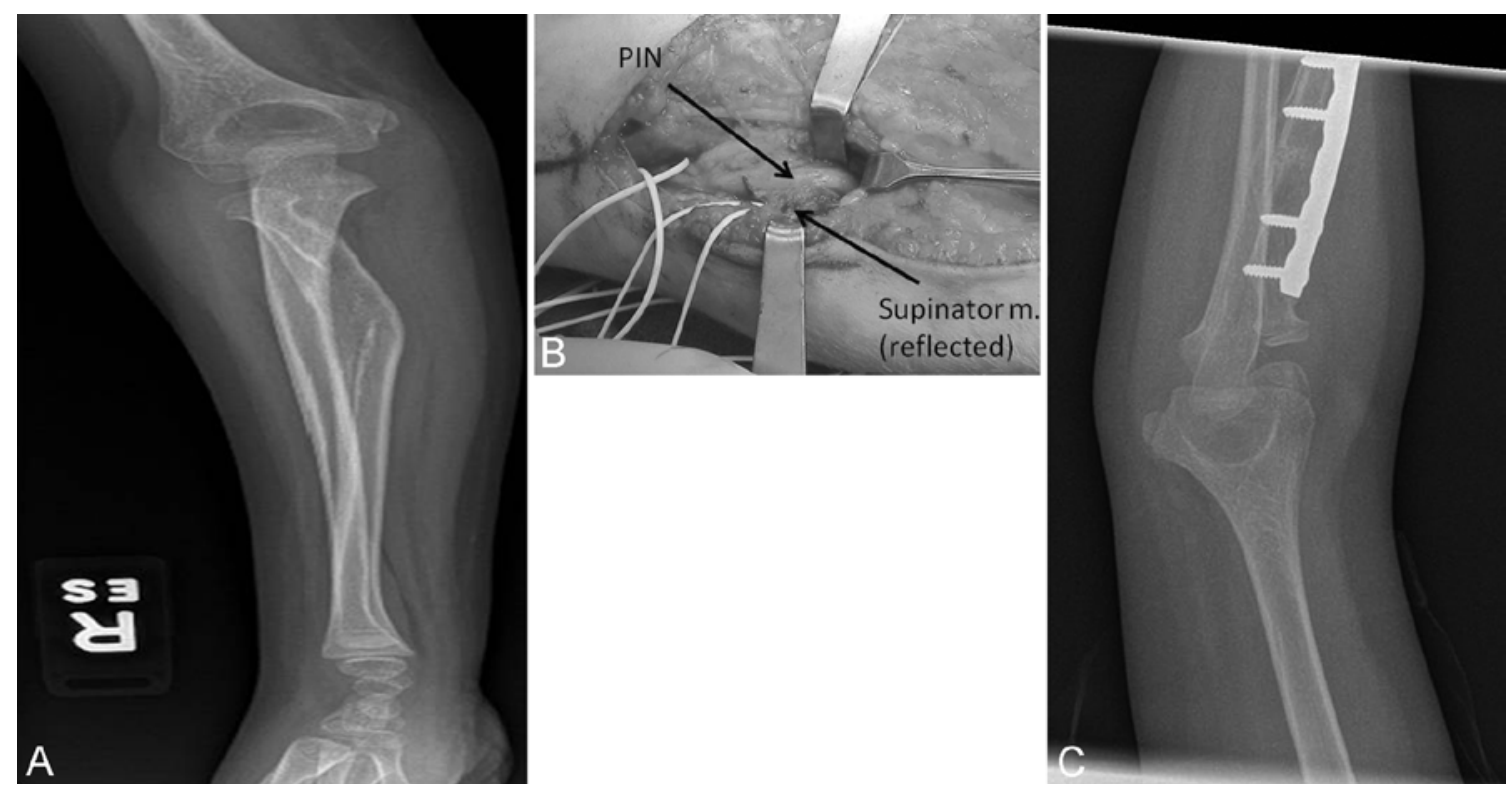

FIG. 2. Images obtained in the patient. A: Preoperative radiograph demonstrating the severe angulation deformity of the proximal radius. B: Intraoperative exposure of the PIN following splitting of the superficial fibers of the supinator muscle. C: Postoperative radiograph showing alignment of the radial deformity with internal fixation. 
cysts, ${ }^{2}$ and myxomas. ${ }^{22}$ Trauma may cause paralysis of this nerve, but many cases of PIN entrapment have no history of antecedent trauma. ${ }^{5}$ The most common site of PIN compression is at the arcade of Frohse, the entrance site of the nerve into the supinator muscle. ${ }^{20}$ Under normal physiological circumstances the proximal PIN is free of compression at the arcade of Frohse. ${ }^{20}$ Other potential but infrequent sites of compression are the tendinous origin of the extensor carpi radialis brevis or the leash of Henry. ${ }^{20}$

Posterior interosseous nerve syndrome from nerve entrapment is primarily a motor syndrome characterized by a reduction or loss of extension of all the digits and atrophy of the posterior forearm muscles with the exclusion of the brachioradialis and extensor carpi radialis longus. ${ }^{4,20}$ Surgical therapy for an entrapped PIN is indicated after 3 months of conservative therapy if functional recovery is absent or if symptoms worsen., ${ }^{1,3,7}$ The proximal PIN is decompressed by dividing the arcade of Frohse, and operative release of the PIN is generally successful. ${ }^{14,15}$ In our case, it was decided at operation that the supinator muscle needed to be released based on the tethering effect that it placed on the PIN with intraoperative range of motion. Parenthetically and in cadavers, median nerve branches to the pronator teres, flexor pollicis longus, and pronator quadratus might be suitable for neurotization of the injured PIN with the hope of restoring wrist extension. ${ }^{21}$ Given the results of the intraoperative nerve stimulation in our case, neurotization was not indicated.

Posterior interosseous nerve palsies in children are uncommon. Within this group, dislocation of the radial head from an earlier fracture should be considered in the differential diagnosis. Based on our case, decompression of the overlying supinator muscle and correction of the radial head instability and radial malunion resulted in return of PIN function and excellent range of motion of the forearm.

\section{Disclosure}

The authors report no conflict of interest concerning the materials or methods used in this study or the findings specified in this paper.

Author contributions to the study and manuscript preparation include the following. Conception and design: Tubbs, Wellons, Conklin. Acquisition of data: Tubbs, Griessenauer, Wellons, Conklin. Analysis and interpretation of data: Tubbs, Griessenauer, Rizk, Pehler, Wellons, Conklin. Drafting the article: all authors. Critically revising the article: all authors. Reviewed submitted version of manuscript: all authors. Approved the final version of the manuscript on behalf of all authors: Tubbs. Administrative/technical/material support: Tubbs, Griessenauer. Study supervision: Tubbs.

\section{References}

1. Botte MJ: Nerve anatomy, in Doyle JR, Botte MJ (eds): Surgical Anatomy of the Hand and Upper Extremity. Philadelphia: Lippincott Williams \& Wilkins, 2003, pp 185-236

2. Bowen TL, Stone KH: Posterior interosseous nerve paralysis caused by a ganglion at the elbow. J Bone Joint Surg Br 48: 774-776, 1966

3. Cravens G, Kline DG: Posterior interosseous nerve palsies. Neurosurgery 27:397-402, 1990

4. Dharapak C, Nimberg GA: Posterior interosseous nerve compression. Report of a case caused by traumatic aneurysm. Clin Orthop Relat Res (101):225-228, 1974
5. Doyle JR: Extensor forearm, in Doyle JR, Botte MJ (eds): Surgical Anatomy of the Hand and Upper Extremity. Philadelphia: Lippincott Williams \& Wilkins, 2003, pp 461-485

6. Ebraheim NA, Jin F, Pulisetti D, Yeasting RA: Quantitative anatomical study of the posterior interosseous nerve. Am J Orthop 29:702-704, 2000

7. Elgafy H, Ebraheim NA, Rezcallah AT, Yeasting RA: Posterior interosseous nerve terminal branches. Clin Orthop Relat Res (376):242-251, 2000

8. Fernandez E, Pallini R, Lauretti L, Scogna A, Di Rienzo A: Neurosurgery of the peripheral nervous system: the posterior interosseous nerve syndrome. Surg Neurol 49:637-639, 1998

9. Grant JCB: An Atlas of Anatomy, ed 2. Baltimore: Williams \& Wilkins, 1947

10. Henry AK: Extensile Exposure, ed 2. Edinburgh: Churchill Livingstone, 1973

11. Lallemand RC, Weller RO: Intraneural neurofibromas involving the posterior interosseous nerve. J Neurol Neurosurg Psychiatry 36:991-996, 1973

12. Loh YC, Stanley JK, Jari S, Trail IA: Neuroma of the distal posterior interosseous nerve. A cause of iatrogenic wrist pain. J Bone Joint Surg Br 80:629-630, 1998

13. Mekhail AO, Ebraheim NA, Jackson WT, Yeasting RA: Anatomic considerations for the anterior exposure of the proximal portion of the radius. J Hand Surg Am 21:794-801, 1996

14. Ozkan M, Bacakoğlu AK, Gül O, Ekin A, Mağden O: Anatomic study of posterior interosseous nerve in the arcade of Frohse. J Shoulder Elbow Surg 8:617-620, 1999

15. Schmidt HM, Lanz U: Surgical Anatomy of the Hand. Stuttgart: Thieme, 2004

16. Sunderland S: Nerves and Nerve Injuries, ed 2. Edinburgh: Churchill Livingstone, 1978

17. Tornetta P III, Hochwald N, Bono C, Grossman M: Anatomy of the posterior interosseous nerve in relation to fixation of the radial head. Clin Orthop Relat Res (345):215-218, 1997

18. Tubbs RS, Jones VL, Loukas M, Cömert A, Shoja MM, Wellons JC III, et al: Anatomy and landmarks for branches of the brachial plexus: a vade mecum. Surg Radiol Anat 32:261270, 2010

19. Tubbs RS, Parmar A, Noordeh N, Rogers C, Rogers N, Loukas $\mathrm{M}$, et al: Surgical anatomy of the radial nerve and profunda brachii artery within the triangular interval. Ital J Anat Embryol 113:129-134, 2008

20. Tubbs RS, Salter EG, Wellons JC III, Blount JP, Oakes WJ: Superficial surgical landmarks for identifying the posterior interosseous nerve. J Neurosurg 104:796-799, 2006

21. Ustün ME, Ogün TC, Büyükmumcu M: Neurotization as an alternative for restoring finger and wrist extension. J Neurosurg 94:795-798, 2001

22. Valer A, Carrera L, Ramirez G: Myxoma causing paralysis of the posterior interosseous nerve. Acta Orthop Belg 59:423425,1993

Manuscript submitted August 16, 2012.

Accepted January 7, 2013.

Please include this information when citing this paper: published online February 1, 2013; DOI: 10.3171/2013.1.PEDS12411.

Supplemental online information:

Video: http://mfile.akamai.com/21490/wmv/digitalwbc.download. akamai.com/21492/wm.digitalsource-na-regional/peds12-411_ video.asx (Media Player).

http://mfile.akamai.com/21488/mov/digitalwbc.download.akamai. com/21492/qt.digitalsource-global/peds12-411_video.mov (Quicktime).

Address correspondence to: R. Shane Tubbs, Ph.D., P.A.-C., JFL 400, Children's of Alabama, 1600 7th Avenue South, Birmingham, Alabama 35233.email: shane.tubbs@chsys.org. 